\title{
Pedro de Valencia, cronista e historiógrafo oficial de las Indias (1607-1620)
}

Jesús Paniagua Pérez

Universidad de León

Pedro de Valencia, discípulo y amigo de Arias Montano, cierra el ciclo del humanismo español de principios del siglo XVII. Fue nombrado cronista de Indias en 1607 y prácticamente su labor indiana era desconocida hasta no hace mucho, por lo que, tras haberse abierto una investigación sobre él, la documentación fluye de continuo para corroborar hipótesis planteadas o para modificarlas. Su labor como tal cronista no fue mucha, puesto que el nombramiento se le hizo casi exclusivamente en función de que recibiese el sueldo como tal, lo que no agradó al otro cronista oficial, Antonio de Herrera, que se quejó de las prebendas de Valencia, protegido directamente por el conde de Lemos.

Pedro de Valencia, del que apenas se sabía nada como cronista de las Indias, brillaba con luz propia en aquella España de Felipe III, tan envuelta en problemas y en crisis. Precisamente coincidiendo con una de las más graves, la bancarrota de 1607, Valencia será nombrado cronista e historiógrafo oficial de las Indias. Era la España del duque de Lerma, caracterizada por el nepotismo del valido y la promoción de personas de poca categoría a los puestos oficiales. Sin embargo, entre ellas hubo algunas de notable valía y reconocido prestigio, como la del hombre que ahora nos ocupa. Pedro de Valencia fue un polígrafo como otros muchos de su tiempo y, sin duda, uno de los intelectuales de más relevancia, querido y admirado por personajes como Céspedes, Arias Montano o Góngora.

Aunque desde el siglo XVIII su figura había tratado de ser revitalizada en varias ocasiones, casi nada se sabía de su labor como cronista de Indias hasta ahora. Carbia le consideró un cronista secundario o menor; ${ }^{1}$ Esteve Barba ni siquiera lo nombra en el conjunto de cronistas oficiales; Schäfer simplemente expresa que su nombramiento se debió a algún motivo personal, por lo que después de su muerte la plaza no volvió a ser proveída. ${ }^{3}$ Todos ellos ignoraron o menospreciaron la actividad de este hompág. 125.

1 Carbia, Rómulo D.: La Crónica Oficial de las Indias Occidentales, Buenos Aires, 1940,

2 Esteve Barba, Francisco: Historiografía Indiana, Madrid, 1964.

3 Schäfer, Ernesto: El Consejo Real y Supremo de las Indias, vol. II, Sevilla, 1947, págs. 412-413.

Tomo LIII, 2, 1996 
bre como cronista, pero hoy se ha podido hacer justicia, porque su obra ha sido descubierta recientemente y publicada ya bajo su nombre. ${ }^{4}$

El reciente estudio de su vida y su obra nos deparó la grata sorpresa de hallar no pocas noticias sobre la labor indiana de Valencia. Parece que sólo llegó a realizar dos obras. Su primera y más importante actividad fue dar forma a las Relaciones Geográficas, que se hicieron siguiendo el cuestionario de 1604. La segunda consistió en recoger información oral y escrita sobre la Historia de la Guerra de Chile, que nunca llegó a tomar forma definitiva, pero cuyos materiales suponemos que utilizó posteriormente Luis Tribaldos de Toledo para realizar su obra Vista general de las continuadas guerras $i$ difícil conquista del gran reino $i$ provincias de Chile. ${ }^{5}$ Cierto es que las Relaciones Geográficas no eran desconocidas, pero nadie había atribuído su autoría a Pedro de Valencia, hasta su reciente publicación. ${ }^{6}$ El hallazgo nos abrió un campo de investigación que por el momento parece no agotarse y continuamente brinda nuevos datos sobre este cronista de Indias. Una vez publicados los dos volúmenes de la obra de Valencia como cronista, han sido localizadas nuevas aportaciones documentales que nos vienen a dar más luz sobre el asunto, bien corroborando lo que en algún momento dábamos como suposición, bien corrigiendo algunas de nuestras hipótesis anteriores.

\section{Breves datos biográficos ${ }^{7}$}

Pedro de Valencia nació en Zafra (Badajoz) el 17 de noviembre de 1555 , en el seno de una familia cuyo padre, Melchor de Valencia, prestaba

4 Valencia, Pedro de: Obras Completas. Relaciones de Indias, León, 1993-1995, 2 vols. La publicación ha sido posible gracias a un equipo interdisciplinario de investigadores de la Universidad de León, bajo la dirección del catedrático de griego de dicha Universidad, Dr. Gaspar Morocho Gayo; todos ellos se hallan empeñados en la publicación de la obra de los humanistas más relevantes, en un proyecto financiado por la Dirección General de Investigación Científica y Técnica.

5 Un manuscrito se halla en la Real Academia de la Historia en un volumen de 210 folios. Real Academia de la Historia: Catálogo de la Colección de Don Juan Bautista Muñoz, vol. I, Madrid, 1954, págs. 202-204.

6 Valencia, Pedro de: Obras Completas...; Morocho Gayo, Gaspar: "El testamento de Pedro de Valencia", Revista de Estudios Extremeños, t. 44, n. ${ }^{1}$, Badajoz, 1988, págs. 9-47.

7 Datos biográficos de este autor pueden verse en las introducciones de los dos volúmenes de su obra americana; Pedro de Valencia, Obras Completas...; y dentro de las mismas obras, en el volumen dedicado a Escritos sociales y económicos, vol. IV/1. Serrano y Sanz, M.: Pedro de Valencia. Estudio biográfico-crítico, Badajoz, 1981. Calderón, R.: "Noticias para su vida", Revista de Estudios Extremeños, Badajoz, 1927, págs. 360-369. Jones, John A.: The Relationship between Benito Arias Montano (1527-1598) and Pedro de Valencia (1555-1620), Leeds, 1970. López Navío, J.: Nuevos datos 
sus servicios a los condes de Feria. En esa localidad se educó con su pariente Antonio Márquez, del que aprendió latinidad. Desde Zafra se trasladó con su familia a Córdoba en 1568, donde estudió en el colegio de los jesuitas, cuando todavía estaban imperantes las ideas del maestro Avila, que había fundado dicha institución.

Una vez acabados sus estudios en Córdoba, en 1572, sus padres decidieron enviarle a la Universidad de Salamanca para que estudiase Leyes, aunque él ya mostraba una clara inclinación por la Teología, materia que presentaba ciertos peligros en aquellos momentos, como él mismo tendría ocasión de comprobar en el tiempo que duró su estancia en la ciudad del Tormes. Durante su permanencia en ella, coincidió con las causas de fray Luis de León, Martínez Cantalapiedra, Gaspar de Grajal, etc. Además, allí tomó clases de griego con otro gran maestro extremeño perseguido por la Inquisición, El Brocense, que probablemente fue quien le introdujo en las tendencias neoestoicas de Justo Lipsio.

Murió su padre en Córdoba, en 1573, mientras él estaba estudiando todavía en Salamanca, y hubo de regresar a Zafra con su madre. De nuevo volvió a la ciudad universitaria castellana para finalizar sus estudios, aunque no llegó a licenciarse, pues, inmediatamente antes de ser nombrado cronista de Indias se pensó en darle un cargo de oficial de Cruzada, y para que pudiera detentarlo hubo de concedérsele la licenciatura que el cargo requería, y que él no poseía. ${ }^{8}$ Es muy probable, si se admite el origen judeoconverso de nuestro hombre, con el que hoy todavía se especula, que no pudiese acceder al grado de licenciado precisamente por esta mácula de su linaje, ya que la Universidad salmantina había cerrado, desde 1522, el acceso a tal grado a todos los que no pudiesen probar su condición de "cristianos viejos".

En 1576 Pedro de Valencia estaba de nuevo en Zafra y allí recibió, desde Lisboa, la Biblia Regia de Benito Arias Montano, la cual le llegó a través de Sebastián Pérez, al que más tarde pediría que le presentase al gran humanista de Fregenal. El zafrense y Arias Montano se conocieron en la

\footnotetext{
sobre Pedro de Valencia y su familia, Badajoz, 1962. Croche de Acuña, F.: "Datos ordenados para una biografía de Pedro de Valencia", Revista de Estudios Extremeños, t. 50, n. ${ }^{\circ}$ 1, Badajoz, 1984, págs. 35-99. Gaspar Morocho Gayo ha publicado varios artículos de los que citaremos los siguientes: "Una historia de Felipe III escrita por Pedro de Valencia", Homenaje al profesor Juan Torres Fontes, Murcia, 1987, págs. 1141-1151; “El testamento...”, págs. 9-47; “Trayectoria humanística de Pedro de Valencia: su actividad en la Escuela de Zafra”, Actas del VII Congreso Español de Estudios Clásicos, Madrid, 1989, págs. 607-612. No se agota con esto toda la abundante bibliografía que hay sobre uno u otro aspecto del humanista de Zafra, tanto en español como en otras lenguas.
}

8 Archivo General de Indias (AGI), Indiferente General, 752. 
Peña de Aracena, probablemente en 1578. En aquel retiro permanecieron juntos hasta septiembre de 1579 y allí parece que el futuro cronista profundizó en los estudios de Sagrada Escritura y en el aprendizaje del hebreo. Después de aquella convivencia, los contactos entre los dos grandes humanistas de Extremadura siguieron siendo muy frecuentes, tanto que el de Zafra ejerció en ocasiones como amanuense de Montano. Parece que su último contacto se produjo en la primavera de 1597, año en que el de Fregenal visitó a Valencia en su casa.

Pedro de Valencia siguió manteniendo su residencia en Zafra, donde se había casado en 1587 con su prima, doña Inés de Ballesteros, de la que tuvo al menos siete hijos. En aquel lugar pasó una buena parte de su vida, dedicado a los estudios de exégesis bíblica y de los clásicos, y a los trabajos de carácter político y económico-social. Mantuvo en su lugar de nacimiento y residencia una buena amistad con los hermanos Machado, algunos de los cuales pasaron a ocupar importantes puestos en la administración americana y, más concretamente, en Quito. Uno de ellos, Fernando Machado, primero fiscal en la ciudad del Pichincha y luego oidor de Chile, dejó a su hijo en España a cargo de su hermano Francisco; pero cuando éste murió, en 1604, el joven pasó a la tutela del personaje que nos ocupa.

Mientras permaneció en Zafra, Pedro de Valencia compuso una buena parte de su obra escrita, sin por ello descuidar la enseñanza de las lenguas clásicas. Allí preparó una edición de las poesías de Montano, a la vez que, tras la muerte del gran humanista, envió algunas de sus obras inéditas a Amberes, para que se publicaran. También fue en esa localidad donde realizó su única obra publicada en vida, los Academica.

Los años que pasaron entre la muerte de Arias Montano, acaecída en 1598, y los de su nombramiento como cronista, fueron difíciles para el zafrense, pues le tocó vivir en su propia piel los problemas de la grave crisis económica por la que pasaban todos los reinos de la Monarquía. En esos años del cambio de centuria fue cuando comenzó a familiarizarse con los temas económicos. Se quejó de los impuestos y de la omnipotencia de los privilegiados. En 1604 declaró la pobreza en la que se hallaba su amigo el padre Sigüenza e impelido por su precaria situación, empezó a preocuparle el valor de las cosas, especialmente de la moneda ${ }^{9}$ y del

9 Biblioteca Nacional (BN), manuscritos 8888, fols. 239-273v.: "Discurso de Pedro de Valencia acerca de la moneda de vellón". Publicado recientemente, se ha editado en Pedro de Valencia: Obras Completas, t. IV-1., págs. 111-123. 
pan. ${ }^{10}$ En relación a este último producto, expondría en uno de sus discursos una de sus ideas más revolucionarias, que su precio debía mantener siempre una relación con el salario de los trabajadores.

En 1607 era nombrado cronista de Indias y de Castilla, el 4 y el 22 de mayo respectivamente, instalando desde entonces su residencia en la Corte. Aquel lugar nunca agradó demasiado a Valencia, por lo que se puede deducir de algunas de sus cartas y memoriales, pero había aceptado residir allí en función de conseguir un mejor futuro para su numerosa familia. En un determinado momento había escrito al respecto a uno de sus amigos, "cuán mal me estaría in hoc saeculo et in futuro la pretensión y la vivienda en la corte, aunque no falta la tentación de la hambre, que propone piedras y otras cosas más duras y pide que hagamos de ellas pan". ${ }^{11}$ Los nombramientos no alteraron su interés por la política nacional, pues es entonces cuando compuso su discurso contra la ociosidad ${ }^{12} \mathrm{e}$, incluso, hizo informes para la Inquisición, criticando la forma en que se llevaban a cabo los interrogatorios y procesos de brujería, ${ }^{13}$ además de enfrentarse a ella, por defender algunos escritos de su maestro Arias Montano. ${ }^{14}$

En 1620, viendo próxima la muerte, decidió hacer su testamento, fechado el 25 de marzo; y el 10 de abril del mismo año entregó su vida a Dios en la villa de Madrid.

\section{El extraño nombramiento de historiógrafo y cronista de Indias}

Pedro de Valencia, aunque había hecho continuos viajes por diferentes lugares de la geografía española, estuvo asentado durante buena parte de su vida en su villa natal de Zafra, donde su familia tenía casa en propiedad. Fue en los años 1606-1607, cuando se vio envuelto en el penoso suceso de fraude del consejero de la Real Hacienda Alonso Ramírez de Prado, primo hermano suyo. Con él compartía Pedro de Valencia un juro

10 Ibídem, fols. 162-238v.: "Discurso sobre el precio del pan". Recientemente se ha editado en Pedro de Valencia: Obras Completas, t. IV-1, págs. 29-71.

11 Ochoa y Ronna, Eugenio de (ed.): Epistolario español: Colección de cartas de españoles ilustres, antiguos y modernos, recogida y ordenada con notas, Madrid, 1870, pág. 44.

12 BN, manuscritos 13348, folios 10v-15, "Discurso Contra la ociosidad". También editado en Pedro de Valencia: Obras Completas, t. IV-1, págs. 159-173.

13 Real Biblioteca de El Escorial (RBE), manuscrito I-III-31, fols. 130-176, "Discurso de Pedro de Valencia acerca de los cuentos de las bruxas".

14 Archivo Histórico Nacional (AHN), Inquisición 4467-38. "Declaración de Pedro de Valencia de los lugares de Arias Montano que se censuran en el Expurgatorio Romano". 
sobre las alcabalas de la ciudad de Ecija, valorado en 2.000 ducados anuales. Sin embargo, él nada sabía de los enredos de su primo, tan sólo había sido utilizado por éste para sus fines de enriquecimiento. ${ }^{15} \mathrm{Al}$ descubrirse el fraude, el juez de la causa, don Fernando Carrillo, solicitó la presencia de Pedro de Valencia en la Corte para averiguar si los dichos 2.000 ducados, que estaban en su cabeza, eran en realidad suyos. ${ }^{16} \mathrm{Si}$ hubo realmente engaño no queda del todo claro en el proceso, pues Pedro de Valencia se ocupó muy directamente de ayudar a la defensa de su primo, aconsejando a su hijo, Lorenzo Ramírez de Prado, ahijado del humanista.

Para entonces Pedro de Valencia tenía una merecida fama y contaba con buenos apoyos entre la nobleza y la intelectualidad del momento; así, don García de Figueroa, de la Cámara de Su Majestad y coterráneo suyo, el cual le presentó al conde de Lemos, para que permaneciese en la Corte. En esa decisión influyeron también otros personajes de relieve, como el condestable de Castilla. Para darle un trabajo que le retuviese, se le encomendó que informase sobre muchos de los libros de El Escorial, cuyo contenido era por entonces desconocido. Este intento de llevarle al monasterio de San Lorenzo corrió, principalmente, de la mano de fray Andrés de San Jerónimo, que luego sería nombrado obispo de Vich.

Pero tras esta misión, y si se quería que el zafrense permaneciese en la corte, había que darle algún tipo de cargo que asegurase su subsistencia y la de su numerosa familia. Se pensó entonces en nombrarle fiscal de Cruzada, cargo para el que se necesitaba el título de licenciado que, al parecer y como ya dijimos, Pedro de Valencia no poseía, y por ello hubo de concedérsele. ${ }^{17}$ Al final, y puesto que la causa contra Ramírez de Prado no había finalizado, fue necesario desistir de darle el cargo mencionado y se hubo de recurrir a otros medios, como el de nombrarle cronista de Castilla y de Indias.

El primer nombramiento que le llega es el de historiógrafo y cronista mayor de Indias, que por entonces detentaba Antonio de Herrera y Tordesillas. Tal nombramiento fue despachado por Felipe III, el 4 de mayo de 1607 y es del tenor siguiente:

"Don Felipe. Teniendo consideración a las muchas letras, erudictión, lectura, ynteligencia de lenguas, continuo estudio y curiosidad en ynquirir y saber la scriptura sagrada, dotores y istoriadores y otras muchas y buenas partes que concurren en vos, el licenciado Pedro de Valencia, y conside-

\footnotetext{
15 Morocho Gayo, Gaspar: "El testamento...”, págs. 38-39.

16 AGI, Indiferente General, 752.

17 Ibídem.
} 
rando lo mucho que ymporta que semejantes personas se ocupen en hazer las historias, por el crédito, autoridad y verdad, que con su escritura se ha de conservar en la memoria de las jentes, he tenido y tengo por bien, de haceros mi chronista ystoriógrapho general de las Yndias Ocidentales, para que podays escriuir la istoria general, moral y natural, assí del decubrimiento de las dichas Yndias, su pacificación y población, echos y cossas memorables que en ella vbieren sucedido y sucedieren, como de las costumbres, ritos y gouierno, y demás cosas dignas de sauerse de sus naturales, propiedades de las tierras, yerbas, plantas y animales, lagunas, fuentes y ríos, y otras cossas tocantes y pertenencientes a la dicha istoria general, así començándola de nuevo como prosiguiendo lo escrito, como mejor os pareciere que conuiene a su perfectión; lo vno y lo otro conforme al horden que se os diere por mi Consejo de las dichas Yndias y así lo quiero y es mi voluntad; y mando que lo podays hacer y hagais, según como lo hazen, pueden y deuen hacer los otros mis chronistas historiográphos destos reynos y de las dichas Yndias, y que goceys y se os guarden todas las honrras, gracias, mercedes, franqueças, libertades, preminencias, prerrogatibas e ynmunidades, que por rraçón del dicho officio debeys hauer y gozar; y por esta mi carta mando al presidente y a los de dicho mi Consejo de las Yndias, que luego que ante ellos sea presentado, tomen y reciuan de vos, el dicho licenciado Pedro de Valencia, el juramento, y con la solenidad que se acostumbra de que bien y fielmente hareis la dicha ystoria, guardando todos los riquisistos que a bueno y fiel historiador tocan y pertenecen, y guardareis secreto en las cosas que se os encargaren y convienen; el qual anssí echo os ayan, reciuan y tengan por mi historiográpho chronista general de los estados y reynos, yslas y prouinçias de las dichas Yndias, y hos agan dar y entregar todas las istorias, scrituras, relaciones, memoriales, cartas, descripçiones y pinturas que vbiere en las secretarías y archiuos del dicho Consejo, así lo que hay al pressente como lo que de estos géneros vbiere y biniere adelante; y lo que vos dijéredes ser necessario, se pida y trayga para que con mayor claridad, noticia y ynteligencia se pueda apurar la berdad que para la dicha istoria se rrequiriere, y que se os acuda con los derechos y distribuciones al dicho officio deuidos y pertenecientes, sin que os falte cossa alguna y que en ello, ni en parte dello, no os pongan ni consientan poner impedimento, no embargante qualquiera cossa que en contrario desto esté proueyda por las hordenanças del dicho Consejo, prouiçiones o cédulas del Rey mi señor, que está en gloria, o mías, que por la presente lo reuoco y anulo, quedando para en lo demás en su fuerça y vigor, 
por cuanto mi determinada voluntad es que lo aquí contenido tenga cumplido efeto, por las causas referidas y bien uniuersal que se sigue de que a semejantes personas se encargue cosa tan importante y que, con la pureça que se espera de vuestra scritura, ha de lucir en estos siglos y los benideros, que yo, por la presente, os reciuo y e por reciuido al dicho officio y al uso y exerciçio de él y os doy poder y facultad para le usar y exercer en caso que por ellos o alguno dellos a él no se aya reciuido. Y es mi merced y boluntad que hayais y lleueys de salario con el dicho officio, residiendo en mi Corte, a razón de quinientos ducados, que valen ciento y ochenta y siete mil y quinientos maravedís cada un año, los quales mando a mi receptor, que al pressente es o adelante fuere, del dicho mi Consejo de las Yndias, que os lo dé y pague de qualesquier maravedís que hubiere y entraren en su poder, de las penas y condenaciones que en él se aplicaren a mi Cámara por los tercios, desde el día en que fuéredes reciuido al dicho officio en adelante, todo el tiempo que le sierviéredes, llevando certificación, al último tercio del año, de mi ynfrasquito secretario de vuestra asistencia y presencia en la Corte y mostrando en el dicho Consejo auer echo en aquel año alguna parte de Historias o preparación para ella y que tome vuestras cartas de pago o de quien vuestro poder hvbiere, con las quales y el traslado signado desta mi provisión, mando se le reciua y pase en quenta lo que en birtud dellas os diere y pagare, sin otro rrecaudo alguno y ansí mismo, mando que tomen la raçón della mis contadores de quentas que residen en el dicho mi Consejo y que, sobrescrita y librada dellos, lo buelua a vos, el dicho licenciado Pedro de Valencia, para que la tengais por vuestro título. Dada en Madrid a 4 de mayo de 1607. Yo el Rey. Yo Pedro de Ledesma, secretario del Rey Nuestro Señor, la fize escriuir por su mandado. El conde de Lemos y de Andrade. El licenciado Venito Valtodano. El licenciado Molina de Medrano. El licenciado don Tomás Ximénez de Ortiz. Licenciado Luis de Salado". ${ }^{18}$

El 11 de mayo de 1607 Pedro de Valencia se presentó con el título de nombramiento y prestó juramento, por lo que es desde esa fecha cuando comenzará a correr su salario, y no desde el día 4 del mismo mes, en que el rey le nombró. ${ }^{19}$ Con todo ello ya no queda duda de que el zafrense fue nombrado oficialmente cronista de Indias, cargo en el que permanecería hasta su muerte, acaecida en 1620.

18 AGI, Indiferente General, 874.

19 Ibídem. 
Su nombramiento como cronista de Castilla fue posterior al de Indias; hubo de esperarse hasta el 22 de mayo para que Felipe III firmase la cédula correspondiente, ya que el Consejo castellano, regido entonces por el conde de Miranda, proclive a la figura de Antonio de Herrera, puso algunos problemas a tal elección. También aquel cargo lo consiguió por influencia del conde de Lemos, yerno del todopoderoso duque de Lerma. El noble gallego, protector de Pedro de Valencia, tenía la pretensión de que se le nombrase cronista general de Castilla con un sueldo de 500 ducados (187.500 maravedís). La Cámara de Castilla no aceptó aquella pretensión y manifestó que el sueldo de cronista era de 80.000 maravedís, por lo que el resto, y puesto que el rey podía disponer de su hacienda, se le abonaría en concepto de ayuda de costa. La Cámara fue todavía más intransigente en la denominación del cargo, ya que no aceptó la de "Cronista General de Castilla", alegando que nadie había disfrutado de aquella titulación, sino simplemente de la de "Cronista de Castilla", y para avalar su negativa adjuntó una lista de prestigiosos nombres que le habían precedido en el ejercicio. ${ }^{20}$ No es nuestro interés aquí tratar los problemas de este cargo, aunque nos ha parecido importante el incluir estos datos, puesto que contribuyen a clarificar la manera forzada en que Pedro de Valencia accedió al ejercicio de cronista oficial.

En el transfondo de estos nombramientos había otras razones ocultas, ya que el humanista de Zafra nunca quiso actuar como cronista, ni de Indias ni de Castilla. Ambas titulaciones eran, sin más, un recurso pactado en la Corte para que Valencia permaneciese en su círculo, teniendo unos ingresos honorables con los que sustentarse él y su familia. Todo ello nos lo revela claramente el propio cronista. ${ }^{21} \mathrm{El}$ manifestará abiertamente en una carta al rey que tales cargos se le daban para entretenerle, en tanto se le ocupaba en otras cosas que le interesaban mucho más. Sólo esa esperanza le llevó a aceptar su cambio de residencia, como él reconoce con claridad: "sino no aceptara este oficio, ni viniera aquí". Ponía como testigos de aquel pacto al conde de Lemos y al condestable de Castilla. Estas condiciones inherentes a su nombramiento - que obviamente no constan en las cédulas reales - parece, según el testimonio de Pedro de Valencia, que las supieron los consejeros de Indias por boca de su protector el conde de Lemos.

20 Todos estos datos constan en el AGI, Indiferente General 752.

21 Ibídem. 
El propio Valencia manifestó el por qué no le agradaba la tarea de cronista:

"porque el ejercicio dél requiere no sólo letras i estudios, sino noticia i esperiencia práctica de negocios de paz i guerra i de los intentos i consejos, sospechas i malicias de los hombres i muy grande actividad y diligencia para informarse de muchas personas i buscar papeles dentro i fuera del reino, y porque aviéndose de tratar la historia con la verdad i entereza que se deve, es forçoso muchas veces censurar las acciones i vidas de los príncipes y de sus ministros i otras personas grandes, reprehender i aun causar infamia a capitanes i soldados i a familias nobles, para en los siglos venideros". ${ }^{22}$

Aún así, no rehusó hacer algunas labores como tal cronista y buen ejemplo de ello son las Relaciones Geográficas, ya publicadas. ${ }^{23}$ Él mismo, en un memorial de 1615, afirma tasativamente que "cumple con la obligación de su officio conforme a su título". ${ }^{24}$ Sin embargo, cobró su sueldos los tres o cuatro primeros años, sin que se le obligara a escribir ninguna historia. Es probablemente después que su benefactor el conde de Lemos abandonara el Consejo, para pasar a ocupar el cargo de virrey de Nápoles, ${ }^{25}$ cuando el de Indias le obligara a escribir las Relaciones, de acuerdo con el modelo que él mismo había elaborado para el conde. ${ }^{26}$ Tras elaborar aquellas descripciones, se le encargó recoger los papeles para escribir la Historia de la Guerra de Chile, para la que tomó relación al maestre de campo Pedro Cortés; pero cuando profundizó en el tema chileno, llegó a la conclusión de que lo mejor para todos era que no se diese más información que la que ya estaba escrita, por las susceptibilidades que ello podría provocar, puesto que "se ha de infamar la nación española de injusticias, avaricia i crueldades, que gustarían mucho de saber los estrangeros, hereges y enemigos de esta Monarquía". ${ }^{27}$

El haber accedido a hacer algunas tareas de cronista, según testimonio del zafrense, le estaba distrayendo de la verdadera razón por la que se le había retenido en la Corte. Lo que él quería en realidad era continuar con

22 Ibídem.

23 Pedro de Valencia: Obras Completas. Relaciones Geográficas...

24 AGI, Indiferente General, 1440.

25 Fue nombrado para tal cargo en diciembre de 1609.

26 Se trataba de la Relación de los Quijos, que el conde de Lemos dedicó al duque de Lerma, de la que ya no nos cabe duda que fue escrita por el autor que nos ocupa. Valencia, P. de: Obras Completas, t. V.-1. Relaciones de Indias, págs. 109-131. de $1616 "$

27 AGI, Indiferente General, 752. "Memorial de Pedro de Valencia de 17 de septiembre 
sus estudios y trabajos de la Biblia y de los clásicos. Reiteradamente expresó su deseo de seguir elaborando las notas y discursos literales que iba escribiendo sobre el Nuevo Testamento y también de defender las versiones que usaba la Iglesia contra los herejes de aquellos tiempos, amén de continuar con otros tratados sobre autores de la Antigüedad. Así lo podían informar los arzobispos de Toledo, de Santiago y de Braga, el obispo electo de Valladolid, el prior de San Lorenzo el Real, los predicadores reales y los catedráticos de Salamanca y Alcalá. ${ }^{28}$ Otro asunto tenía entonces muy ocupado a Pedro de Valencia, aunque no hace alusión a él: la controversia abierta sobre el Pergamino y Láminas de Granada, en la que él lideraba el grupo contrario al arzobispo Pedro de Castro.

Parece que Pedro de Valencia, a partir de 1616, ya no estaba dispuesto a continuar con sus labores de cronista y reclamó al rey que se le respetaran las condiciones tácitas iniciales, con las que se le había dado tal cargo. Por tanto, rogaba que se le siguiese manteniendo el sueldo de cronista de Indias sin ejercer de tal, condición por la que se había quedado en la Corte. El rey pasó el memorial al Consejo y no parece que tuviese mucho éxito, pues en su testamento Pedro de Valencia expresa: "se me mandó por parte de Su Magestad me viniese a esta Corte, con promesa de que sería honrado y entretenido y sustentado con mi familia en ella, de manera que por lo menos no me fuese mal de auer uenido; y esta promesa se me fue confirmando, pero no llegó a efecto su cumplimiento". ${ }^{29}$ Aunque, por otro, como cronista de Indias, no tenemos noticia de nuevos escritos americanistas debidos a su pluma, aparte de los referenciados.

\section{Pedro de Valencia y Antonio de Herrera}

No es de extrañar que nos planteemos el por qué se nombró a Pedro de Valencia historiógrafo y cronista de Indias, cuando ya estaba cumpliendo esa tarea Antonio de Herrera y Tordesillas. Este último había entrado como cronista en tiempos del rey Felipe II (15 de mayo de 1596), pero no debió ser del agrado del conde de Lemos, presidente del Consejo de Indias desde 1603, que no ocultó su antipatía por el de Cuéllar. Tampoco Antonio de Herrera disimuló la poca consideración que sentía por el conde, apoyándose en ocasiones en la protección que le prestaba el de Miranda, presi-

28 Ibídem.

29 Morocho Gayo, Gaspar: El testamento..., pág. 20. 
dente del Consejo de Castilla. Malos tiempos vinieron para Herrera con el nombramiento de Lemos, después de que hubiese gozado de las simpatías del presidente Pablo de Laguna, predecesor del conde gallego, al que hizo, en 1601, una dedicatoria de sus cuatro primeras Décadas. ${ }^{30}$

Probablemente, Pedro Fernández de Castro, conde de Lemos, cuando se planteó la conveniencia de recolocar a Pedro de Valencia en la Corte para retenerle en ella, pensó desde un principio en los cargos de cronista de Indias y de Castilla. Valencia era, sin duda, un hombre de más valía intelectual que Herrera, y sabía el noble gallego que aquella designación le iba a doler al segoviano, sobre todo porque iba a hacerle entrar en el Consejo de Indias con mayores prebendas económicas y laborales.

Ciertamente, los supuestos de Lemos se confirmaron. La polémica que iba a suscitar Antonio de Herrera tendría dos puntos fuertes: el salario superior de Pedro de Valencia y la menor cantidad de trabajo que desarrollaba el zafrense.

Pero las quejas de Herrera por cuestiones económicas no eran nuevas. Ya cuando se le había nombrado cronista de Indias no se dio por satisfecho con su salario y había recurrido al conde de Miranda, que consiguió para él, el título de cronista de Castilla, en 1598, con 80.000 maravedís de salario, tal y como estaba prescrito para tal cargo. No es de extrañar que al susodicho presidente del Consejo de Castilla dedicase parte de su Historia General del Mundo, editada en $1601 .^{31}$ En ese mismo año publicó también una traducción del italiano de una obra del cardenal de Fermo, dedicada a la esposa de su protector, la condesa de Miranda, doña María de Zúñiga Avellaneda y Bazán. ${ }^{32}$

La cuestión del nombramiento de Valencia no abría nuevas heridas en las relaciones de Herrera con el conde de Lemos, sencillamente ahondaba en las ya existentes y en el convencimiento de haberse sentido siempre poco protegido por algunas autoridades de Indias. La única recompensa oficial que el de Cuéllar había tenido hasta entonces sobre su sueldo como cronista de Indias habían sido de 1500 ducados, librados por una vez, cuando se imprimieron las cuatro primeras Décadas, ${ }^{33}$ cosa que sucedió en 1601. Tal dinero se le concedió sobre los oficios vendibles de la Nueva

30 Herrera y Tordesillas, Antonio de: Historia General de los hechos de los castellanos en las Islas y Tierra Firme del mar Océano o "Décadas”, Madrid, 1991, volumen I, págs. 128-129.

31 Segunda parte de la Historia General del Mundo, Madrid, 1601.

32 Cardenal de Fermo: Batalla espiritual y arte de servir a Dios, Madrid, 1601.

33 AGI, Indiferente General, 752. 
España, por lo que tuvo que hacer un poder el 9 de febrero de 1605 a Alonso de Oñate, vecino de México, para poder cobrar la citada cantidad; ${ }^{34}$ sin embargo, en la documentación, Herrera manifiesta haber cobrado solamente 1200 ducados, ya que los otros 300 tuvo que utilizarlos en los gastos de traslado del numerario. Recurrió entonces a quejarse al conde de Lemos de la escasez de aquella recompensa. El conde le contestó, con manifiesta socarronería, que aquello no era una gratificación, sino fondos para papel y tinta con el fin de que acabase su Historia de las Indias y que, una vez que la finalizase, sería bien proveído. ${ }^{35}$

Cuando el de Zafra fue nombrado cronista de Indias, Herrera dirigió sus armas contra él, en sus reclamaciones pecuniarias, poniendo de manifiesto la injusticia que se sentaba en las diferencias de trabajo y de sueldo. De nuevo chocó con el conde de Lemos en 1609 y esta vez con mayor gravedad, ya que cuando Herrera dijo que se le estaba haciendo una injusticia, fue prendido y, aunque no cumplió la prisión estipulada, "fue forzado a suplicar en el Consejo de Indias, de donde resultó lo referido". ${ }^{36}$

En la segunda década de la centuria, cuando ya el conde de Lemos no estaba al frente del Consejo de Indias, sino que era don Luis de Velasco (1611-1617) quien lo regentaba, Antonio de Herrera volvió a las andadas, quizá con mayores esperanzas. Entonces aprovechó para poner en evidencia a Pedro de Valencia, diciendo que sin trabajar cobraba 100 ducados más que él (Herrera tenía un sueldo de 400 ducados y Pedro de Valencia de 500). Los miembros del Consejo, movidos por sus quejas, llegaron a solicitar para el de Cuéllar que se le concedieran 300 ducados de renta más cada año y dos mil ducados de ayuda de costa, por una vez.

En el aspecto económico Herrera se quejaba siempre de la diferencia de salarios y de que a Valencia se le hubiesen concedido 500 ducados por una vez para trasladar su casa a la Corte. A estas "afrentas" fue añadiendo la serie de prebendas que se iban otorgando al de Zafra, tales como los 400 ducados anuales de renta en las arcas del tesoro, que se le concedieron en 1614 , porque pasaba necesidad, ${ }^{37}$ y los 300 que se dieron de renta a un hijo minusválido, además de concederle al cronista "médico y botica". ${ }^{38}$

34 Cuesta Domingo, Mariano, en Herrera y Tordesillas, Antonio de: Historia General..., pág. 111.

35 AGI, Indiferente General, 752.

36 Ibídem.

37 Ibídem.

38 Ibídem.

Tomo LIII, 2, 1996 
Pero el de Cuéllar no sólo alegaba cuestiones económicas, sino también de trabajo. Se lamentaba de todos los beneficios que obtenía Valencia "sin haber sacado a la luz ninguna parte de historia". ${ }^{39}$ Sin duda, Herrera desconocía el transfondo que había en el nombramiento del zafrense. De todos modos, con la salida del de Lemos del Consejo, Pedro de Valencia se vio obligado a hacer algunas tareas de cronista, como ya dijimos, para contento de su oponente y disgusto propio, como manifiesta en las quejas elevadas al rey, alegando que aquello no era lo pactado.

No conocemos hasta el momento respuestas de Pedro de Valencia a todas las insinuaciones vertidas por Antonio de Herrera. Sin duda, el zafrense se sentía protegido en la Corte y no veía ninguna necesidad de enfrentarse a Herrera abiertamente; sus servicios debían ser considerados más valiosos que los del segoviano, como hombre entendido en asuntos prácticos del reino, y de una valía intelectual reconocida por casi todos los grandes del momento. Es por ello que, en sus memoriales, nunca cita al otro cronista, ni para bien ni para mal, en un intencionado afán de ignorarle. Ni siquiera llegamos a tener constancia de que elevase algún tipo de queja por no tenérsele en cuenta en las colaciones que cada año daba el Consejo de Indias a sus miembros, en el día de San Juan, y de las que sí era partícipe Antonio de Herrera. ${ }^{40}$

Pero no todo lo que distanciaba a los dos cronistas estaba directamente relacionado con las tareas del Consejo de Indias. En la España de aquel momento, uno de los temas que más llamaba la atención de todos los sectores de la población era, sin duda, el problema del Pergamino y Láminas de Granada. Con él tuvieron también que ver estos dos hombres, aunque mucho más de cerca Pedro de Valencia, que había sido un abierto denunciador de todo aquel fraude pseudorreligioso, ${ }^{41}$ montado en torno a la figura de Pedro de Castro y Quiñones, hijo del que había sido gobernador del Perú, Cristóbal Vaca de Castro. Herrera, que sería autor de una obra sobre el citado padre del mitrado granadino, titulada Elogio de el Licenciado Cristóval Vaca de Castro, del Consejo Supremo y Governador de los Reynos del Pirú, ${ }^{42}$ no tuvo ningún recato en seguir la corriente al arzobispo de Granada

39 Ibídem.

40 AGI, Indiferente General, 1442, 1444 y 1446.

41 Sobre la relación de Pedro de Valencia con el problema del Pergamino y Láminas de Granada, puede verse Morocho Gayo, Gaspar: "Pedro de Valencia en la historia de la traducción del Pergamino y Láminas de Granada", Livius, 2, León, 1992, págs. 107-137.

42 Herrera y Tordesillas, Antonio de: "Elogio de Vaca de Castro", Revista de Archivos, Bibliotecas y Museos, núms. 36-38, Madrid, 1917-1918. 
cuando le interesó; y, así, dice en una carta de 30 de enero de 1623 dirigida al prelado: "sobre engrandecer el Monte Sacro no dixe nada dél en la dirección del elogio a V. S. Illma., por parecerme que en aquel lugar se podía dezir poco, pero visto lo que V. S. Illma. manda, he pensado de hazer un breve discurso al fin de toda la obra". ${ }^{43}$ Para entonces, Pedro de Valencia ya había muerto, pero se había puesto de manifiesto su oposición en este asunto al arzobispo Pedro de Castro e, incluso, sus reparos a la publicación de algunas obras que ponían de relieve el valor de tales hallazgos. ${ }^{44}$

En asuntos de Historia los dos cronistas también manifestaron sus diferencias. Pedro de Valencia, se muestra como un intelectual al que no le gusta escribir sobre temas de esa índole, puesto que considera esa materia como una ciencia de la verdad, en la que nada podía ser ocultado; para él la historia suponía tener "noticia y experiencia práctica de negocios de paz y de guerra y de los intentos y conflictos, sospechas, malicias de los hombres, y muy grande actividad y diligencia para informarse de muchas personas y buscar papeles dentro y fuera del reino". Para Valencia la historia exigía tener el mayor grado de información posible, y esto no sólo lo manifestó en el caso de Chile, sino también cuando hubo de informar de los papeles de Alonso Sánchez sobre China, de los que sostuvo que "quando se uviese de escribir alguna historia de la China, sería menester juntar muchos más papeles i todas las relaciones i libros pertenencientes a la materia. Lo qual toca más derechamente al Consejo de Portugal i a sus cronistas". ${ }^{45}$ Además, él consideró la historia como una ciencia y, como tal, sujeta a la crítica de la razón, alegando que ésta debía tratarse siempre con verdad y entereza y "es forzoso muchas veces conjurar las acciones y vidas de los príncipes y sus ministros". ${ }^{46}$ No es de extrañar, por tanto, que en un mundo de influencias, donde la vida dependía del agrado o desagrado de los grandes, Valencia evitase manifestarse y caer en la trampa que podía serle tendida por cualquier parte, cuando su posición no era del todo cómoda.

Se ha hablado, por otro lado, de la imparcialidad de Herrera, pero no creemos que ésta fuera tanta, habida cuenta de que no dudó en elogiar la figura de Cristóbal Vaca de Castro, cuando se lo solicitó su hijo, don Pedro

43 Ibídem, 36, pág. 14.

44 Dos de esas obras fueron la de Cabrera de Córdoba, Luis: Historia de Felipe II, Madrid, 1857; y la de Jiménez Patón, Bartolomé: Mercurius Trimegistus, Baeza, 1621.

45 British Library (BL), Manuscripts ADD. 13977. Jones, John A.:"Pedro de Valencia en su correspondencia: carta y relación de unos papeles de Alonso Sánchez", Boletín de la Real Academia Española, 65-234, Madrid, 1985, pág. 142.

46 AGI, Indiferente General, 752. 
de Castro y Quiñones, poderoso e influente hombre de la España del momento. Cierto que Vaca de Castro había sido exculpado de los cargos que se le hicieron de su estancia al frente de los asuntos del Perú. ${ }^{47}$ Pero, consultando la documentación de la época y analizando los hechos, no queda duda de que el leonés no estaba libre de muchas de las culpas que se le imputaron y que su afán de enriquecimiento había sobrepasado todos los límites. Para rehabilitar su figura contó con un hijo como don Pedro, que desde su omnipotente puesto en la Chancillería de Valladolid y en los arzobispados de Granada y Sevilla se lanzó a una rehabilitación propagandística de la figura paterna, contando para ello con panegiristas de la altura del famoso Calvete de la Estrella, que le dedicó sus Vaccaeis. ${ }^{48}$ En ese mismo juego entró el propio Herrera en la obra que hemos citado con anterioridad, sobre la que llegó a escribir al arzobispo: "V. S. Illma. será servido de ver el elogio y mandármelo volver acomodado, conforme a su voluntad, pues será lo mejor y más acertado". ${ }^{49}$

Estamos pues ante dos hombres, que aún siendo humanistas de primera fila, presentan dos vertientes muy distintas del humanismo y reflejan los enfrentamientos que latían en el círculo cortesano de Felipe III, manifestándose en dos parcialidades, una proclive a Herrera y la otra a Valencia. Ninguno de los bandos mejor ni peor y, en medio, estos intelectuales que cierran el humanismo español de los primeros decenios del siglo XVII, utilizados como armas arrojadizas en uno y otro sentido. Valencia, sin embargo, era menos proclive a dejarse influenciar que su compañero, el cronista Herrera, quizá porque gozaba de un mayor reconocimiento entre los grandes intelectuales de su tiempo, pues no en vano era el heredero intelectual de Benito Arias Montano, cosa que algunos sectores, sobre todo eclesiásticos, no le iban a perdonar.

\section{La labor americanista de Pedro de Valencia}

La labor americanista de Pedro de Valencia, hasta el momento, podemos centrarla en tres aspectos: la elaboración de sus Relaciones

47 Sobre este aspecto puede verse la obra de M. I. Viforcos Marinas y J. Paniagua Pérez: El leonés don Cristóbal Vaca de Castro, gobernador y organizador del Perú, Madrid, 1991.

48 Archivo del Sacromonte de Granada (ASG). Allí, entre los papeles del arzobispo, se conserva un manuscrito de esta obra. Ioan Christophori/ Calveti Stellae ad/ Petrum Castrum Quinnonium/ Granatae Archiepiscopum./ Vaccaeis/ [escudo arzobispal de don Pedro] Salmanticae/ Idibus Ian. An. Virginei partus./MDXC./.

49 Herrera y Tordesillas, Antonio: “Elogio...” 36, pág. 15. 
Geográficas, sin duda su obra máxima en esta temática; su inacabada Historia de la Guerra de Chile; y las aprobaciones que dio para algunas obras de tema americanista de gran relieve.

Que su cargo de cronista no llevaba implícita la obligación de trabajo alguno, dice el autor que nos ocupa, que fue público y que los señores del Consejo conocían esta excepcionalidad por boca del conde de Lemos. Por ello durante los tres o cuatro primeros años no desarrolló ninguna tarea de cronista, a pesar de que se le libró su sueldo (1607-1609). Aún así, hubo de realizar algunas labores históricas, puesto que el rey no le encargó ninguna de las tareas que supuestamente debía realizar y que tendrían que ver con los estudios de los clásicos y con algunos asuntos eclesiásticos, temas en los que él reconocía ser verdaderamente un entendido.

Debido a esta inactividad, cuando la presidencia del Consejo dejó de ser ejercida por el conde de Lemos, se le encargó hacer las Relaciones Geográficas de Indias, en las que se debían tratar las respuestas al cuestionario elaborado en 1604. La tarea no era del todo nueva para él, pues, en 1608, ya había elaborado para el citado noble la Relación de los Quijos, dedicada al duque de Lerma, y, como parece que la forma en que la escribió había agradado, comenzó la elaboración según aquel modelo. Todo ello nos hace suponer que la redacción definitiva de tales Relaciones no se comenzó hasta 1610.

Una vez finalizado aquel trabajo, en 1613, se le mandó que recogiese los papeles necesarios para escribir la Historia de la Guerra de Chile, ${ }^{50}$ una de las cuestiones que más preocupaba en aquel momento de los asuntos de Indias, como dice el propio Pedro de Valencia, "Por ser esta parte de historia la más principal entre las cosas de las Indias". ${ }^{51}$ Temporalmente, esta historia interesaba desde el año 1598, en que había muerto Martín García de Loyola. La tarea que se le encargó fue comenzada, de hecho, llegó a tomar declaración al capitán Pedro Cortés, que por entonces se hallaba en la Corte, e incluso copió y sacó relación de muchos papeles, relaciones y cartas de los virreyes de Perú y de los gobernadores de Chile..$^{52}$

Cuando parecía que ya tenía material suficiente, Pedro de Valencia se negó a continuar con este último trabajo, después de que en el memorial de 1616 solicitase el pago de su salario y que se le entregase más documentación, "para que yo me ocupe este presente año de 1616 y cumpla con mis

50 AGI, Indiferente General, 1443.

51 AGI, Indiferente General, 1440.

52 AGI, Indiferente General, 1443. 
obligaciones y con el servicio de V.A.." ${ }^{53}$ Alegaba, como dijimos, que no era aquella la labor por la que se le había hecho cronista y, también, su particular concepción sobre la imparcialidad en asuntos de historia y su resistencia a tomar partido, confesada al afirmar que "haciendo en ella el deber del oficio de historiador se han de ofender personas de calidad y sus hijos y familias y se ha de infamar la nación española de injusticias, avaricia y crueldades, que gustarían mucho de saber los extranjeros, herejes y enemigos de esta monarquía". ${ }^{54}$ No creía, pues, que fuese conveniente dar más noticia de todos aquellos sucesos del hemisferio sur.

Su historia de Chile, por tanto, nunca llegó a tomar un cuerpo definitivo y sería continuada por don Luis Tribaldos de Toledo, que es muy probable que simplemente aprovechase el material que le había dejado Pedro de Valencia, aunque no utilizase aquella copiosa documentación con toda la conveniencia que debía.

Como cronista de Castilla, que también lo era Pedro de Valencia, le tocaba dar su aprobación para la publicación de algunos libros. De entre los varios que informó, algunos eran de tema americanista, que son los que aquí nos interesan. Uno de los primeros de los que tenemos noticia hasta el momento fue el de Bartolomé Leonardo de Argensola, ${ }^{55}$ al que dio su aprobación el 4 de enero de 1609; precisamente Argensola era otro protegido del conde de Lemos, al que éste había llevado consigo cuando fue nombrado virrey de Nápoles.

La aprobación más polémica que hizo fue, quizá, la de la obra de fray Juan de Torquemada. Se trataba de su Monarquía Indiana, a la que Herrera había despreciado. Pedro de Valencia dio su aprobación para la publicación de esta obra el 5 de mayo de 1613. ${ }^{56}$ Para justificar aquella concesión, que probablemente ya había sido denostada por el citado cronista segoviano, aclaró que no contenía nada contra la fe y buenas costumbres y que, al contrario, servía para la edificación de la Iglesia y gloria del Nombre de Dios, ya que daba noticia de historias, costumbres, ceremonias y gobierno de los indios, de acuerdo con sus antiguas tradiciones y las pinturas conservadas de los mismos. ¿Conocía Valencia la existencia de la Historia Eclesiástica Indiana de Jerónimo de Mendieta, en la que se había alimentado en buena

53 Ibídem.

54 AGI, Indiferente General, 752.

55 Argensola, Bartolomé Leonardo de: Conqvista de las Islas Malvcas, Madrid, 1609.

56 Torquemada, Fray Juan de: Los veynte y un libros rituales y Monarchia Indiana, Sevilla, 1615. Una segunda edición de esta obra se realizó en Madrid en 1723 y más recientemente en México en 1969 y 1975. 
medida la Monarquía Indiana de su compañero de Orden? Es un interrogante al que hasta el momento no podemos responder, puesto que al ser una obra inédita, no necesariamente tenía que haber pasado por sus manos.

Aprobó también la obra de Suárez de Figueroa, Historia y Añal, que trataba sobre la expansión de los jesuitas en el Oriente, a principios del siglo XVII. ${ }^{57}$ Este tema de Oriente no sabemos hasta qué punto interesó a Valencia, puesto que estuvo muy relacionado con él, sobre todo por las informaciones de obras que en ese sentido se le solicitaron.

El 6 de enero de 1614 daba su aprobación para otra obra del Inca Garcilaso de la Vega: se trataba de la segunda parte de los Comentarios Reales de los Incas, que salió con el título de Historia General del Perú, para la que Valencia dio su aprobación, por encargo del Consejo de Castilla, en la citada fecha. ${ }^{58}$ Sin lugar a dudas, de las obras americanistas por él informadas esta ha sido la que más transcendencia ha tenido hasta el momento y sobre la que más tinta se ha vertido.

Otra obra de contenido netamente español, pero con alusiones de importancia al mundo americano y que aprobó Pedro de Valencia, fue la de fray Pedro de Salazar sobre la historia de una de las provincias franciscanas de España. ${ }^{9}$

No debemos olvidar, antes de concluir, el informe que sobre los papeles del jesuita Alonso Sánchez tuvo que dar al Consejo, ${ }^{60}$ aunque sea anterior a las aprobaciones de obras que hemos mencionado, ya que se trata de un documento de 21 de diciembre de 1609. En él pone muchas pegas a los escritos del jesuita e incluso manifiesta algunas de sus ideas sobre el problema de los descubrimientos y conquista, con los que él está de acuerdo, en función de la propagación de la fe, si bien matiza "aunque los ministros hayan sido llevados en sus intentos de otros menores fines". ${ }^{61}$

57 Suárez de Figueroa, Cristóbal: Historia y añal relación. De las cosas que hicieron los padres de la Compañía de Iesús por las partes del Oriente y otras en la propagación del Santo Evangelio, Madrid, 1614.

58 Garcilaso de la Vega (El Inca): Historia General del Perv, Córdoba, 1617.

59 Salazar, Fray Pedro de: Crónica y Historia de la fundación y progresso de la Provincia de Castilla, de la Orden del bienauenturado padre San Francisco, Madrid, 1612.

60 BL, Manuscripts ADD. 13977, fols. 644-654v. De estos papeles, ya ha sido publicada la carta de Pedro de Valencia, que incluyen en el folio 644. Jones, John A.: "Pedro de Valencia en su correspondencia...”, págs. 141-142.

61 Ibídem, folio 646. No nos extenderemos más en este punto, puesto que el memorial y su comentario será publicado pronto en la edición de las Obras Completas de Pedro de Valencia. 